\title{
Note
}

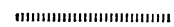

\section{Beam Test Results of Small AVF-Cyclotron for Radioisotope Production ${ }^{\dagger}$}

\author{
Kazuo FUJII and Yukio Kumata \\ Niihama Works, Sumitomo Heavy Industries, Ltd. \\ 5-2, Soubiraki-cho, Niihama-shi, Ehime Pref. 792 \\ Received October 9, 1981
}

Key Words: azimuthally varying field cyclotron, beam control system, stability of the beam

\section{Introduction}

The importance of short-lived positron emitting radioisotopes like ${ }^{11} \mathrm{C},{ }^{13} \mathrm{~N},{ }^{15} \mathrm{O}$ and ${ }^{18} \mathrm{~F}$ have been increased, as positron camera has been developed in the field of the emission computerized tomography. Sumitomo Heavy Industries, Ltd. has recently developed an AVF-cyclotron (azimuthally varying field cyclotron)named CYPRIS which is dedicated to the production of these short-lived radioisotopes, in cooperation with CGR-MeV in France. This machine can deliver $15 \mathrm{MeV}$ proton and $8 \mathrm{MeV}$ deuteron. The extracted beam current of $50 \mu \mathrm{A}$ is guaranteed for both particles. These specifications are sufficient to insure the yield of the radioisotopes enough for most of the medical applications. The detailed description of the characteristics of CYPRIS is given in ref. ${ }^{1)}$

We made some specific efforts to simplify the structure of the cyclotron and also to ensure an easy operation, because we supposed that an easy operation of a medical cyclotron is the most important factor for the pharmaceutical or medical people. Recently we succeeded in obtaining the guaranteed beam current on the target of the first machine. The excellent stability of the extracted beam current was also achieved.

The beam test results are briefly presented in this paper, with a brief description of the prin-

† シジオアイソトープ製造用小型 AVF サイクロト ロンのビームテストの結果。藤居一男, 熊田幸生

: 住友重機械工業(㑣新居浜製造所, 792 愛媛県新 居浜市惣開町 5-2 ciple of the control method which differs from the traditional one.

\section{Control Methods}

2.1 Radio-Frequency system (RF system) The number of mechanical components should be minimized to realize a simple and easy operation. Single- $180^{\circ}$-dee system was adopted to simplify the RF system, although two-dee-system had been usually used for the design of the medium energy cyclotron.

In the conventional cyclotrons mainly applied to nuclear physics, the frequency drift of the $\mathrm{RF}$ resonator is compensated by the mechanical movement of the shorting plane or the capacitive compensator. In CYPRIS, instead, it is followed by the electrical frequency tracking of the master oscillator. Figure 1 shows the block diagram of the RF system for CYPRIS. In this

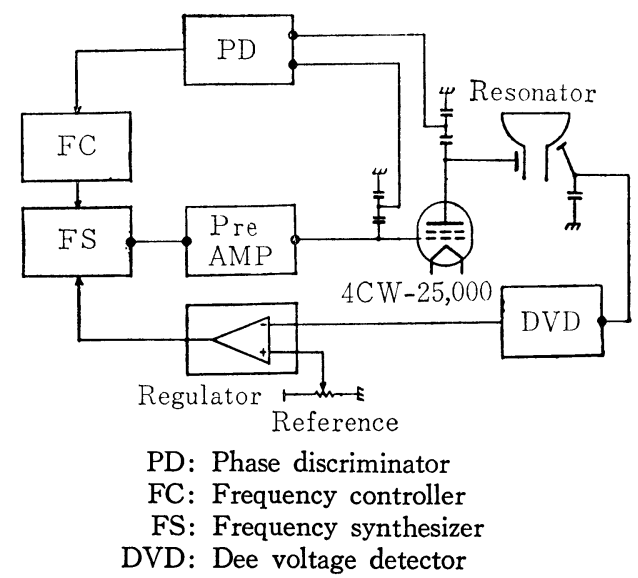

Fig. 1 Block diagram of RF system. 
scheme, the frequency of the synthesizer is controled by a feed-back signal derived from the phase difference between the grid and plate RF voltage of the power tube which reflects the error of frequency tuning of the dee system.

The frequency tracking is all electronic and no movable mechanical parts are involved while in conventional systems the feed-back-loops necessarily include the capacity compensators or other mechanical devices as stated above. Whereas present method is free from the troubles originating from the use of motors or movable vacuum feed-throughs; there are no problems caused by the large difference in response time of the elements in the feed-back loops. Operation is easier and maintenance work is simpler than the conventional scheme. Of course, this method is only applicable to the single dee system as CYPRIS and can not be used in the systems using complex number of resonators.

It might be feared that the frequency change allowed in this scheme would induce a moderate energy and intensity variation of the beam on the target. Our beam test has confirmed, however, that the quantity of energy drift can well be neglected after 10 minutes have passed from the dee voltage establishment. The test results is shown in Fig. 2. This figure gives the description of the RF frequency drift at $40.5 \mathrm{MHz}$ in case of deuteron acceleration. The horizontal axis indicates the time after the establishment of the dee voltage. The vertical axis represents the tuned frequency. It is noted that the total frequency drift is less than $0.2 \%$. There is a large frequency drift for the first 3 minutes.

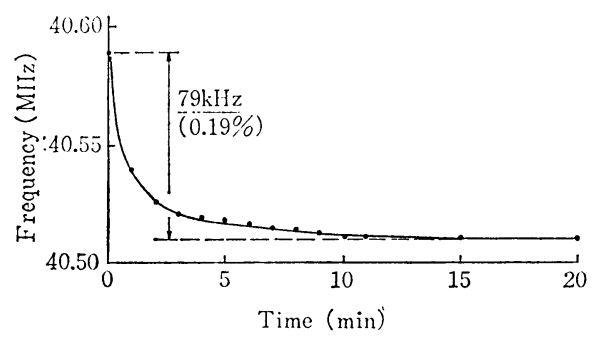

Fig. 2 RF frequency drift.

The frequency is for deuteron acceleration. The dee voltage is $25 \mathrm{kV}$. The temperature of cooling water is regulated at $28 \pm 0.5$ ${ }^{\circ} \mathrm{C}$. The quantity of the frequency drift is less than $0.2 \%$.
During this period, the resonator gets thermal deformation with the onset of the RF heating. But 10 minutes later, the drift decreased to a negligible amount, probably because a thermal equilibrium was established rapidly in the resonator and its temperatures got stabilized by virtue of the accurate control of the cooling water temperature at $28 \pm 0.5^{\circ} \mathrm{C}$. No further deformation seems to occur. Thus, 3 minutes after the dee voltage establishment, the ion source can be started, since it is very certain that the beam energy drift is small. The situation is almost the same also for $26 \mathrm{MHz}$ for proton acceleration.

\section{$2 \cdot 2$ Beam control system}

The frequency of the master oscillator varies according to the frequency drift of the resonator, though it is very small. Therefore the magnetic field should be changed in order to stabilize the extracted beam current. The beam control system for CYPRIS is so designed as to automatically adjust the magnetic field to compensate the effect of the frequency drift. This is also very desirable to get an easy operation. Our beam control system makes it possible to position the beam on the target or on the beam shutter, which is located in front of the target system, without any manual adjustment of the magnetic field. The beam control procedure is briefly described below.

A pair of auxiliary coils are assembled around the magnet poles besides the main coils to facilitate the control of the beam. They can control the magnetic field within the narrow range. Figure 3 gives the resonant aspect of the extracted beam current $v s$. the magnetic field. Our

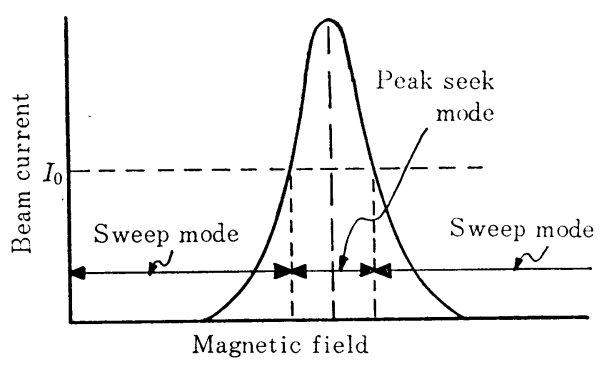

Fig. 3 Resonant aspect of extracted beam current $v s$. magnetic field. $I_{0}$ is an easily adjustable parameter. 
beam control procedure consists of two modes. One is "sweep mode" which may be selected when the beam current detected on the target or on the beam shutter is smaller than $I_{0}$. In this mode, the auxiliary coil current is increased or decreased gradually for finding the beam current above $I_{0}$ on the target or on the beam shutter. The other is "peak seek mode" which may be selected automatically when the beam current detected on the target or on the beam shutter is larger than $I_{0}$. In the mode, the auxiliary coil current is changed so as to hold the beam current at the peak value on the target or on the beam shutter.

\section{Beam Test Results}

Figure 4 and 5 show the stability of the extracted beam current obtained by the control methods described above for proton and deuteron respectively. They were measured on the beam shutter. The guaranteed beam current of $50 \mu \mathrm{A}$ was obtained for both particles. The duration of measurement was above 30 minutes for both of them. The amount of the fluctuation in the extracted beam current observed is approximately within $\pm 1 \mu \mathrm{A}$. This fluctuation seems to have some correlation with the stability of gas flow rate to the ion source. However, this fluctuation gives little effect to the radioisotope production.

\section{Summary}

Results of the beam test of a cyclotron of which RF system and beam control methods have been designed to simplify operation are described. The stability of beam and simpleness of operation are satisfactory and fulfil the aim of design. All one has to do to operate CYPRIS is pushing 4 push buttons, choosing 2 selection buttons that select the kind of accelerated particle and the target number, and adjusting a potentiometer

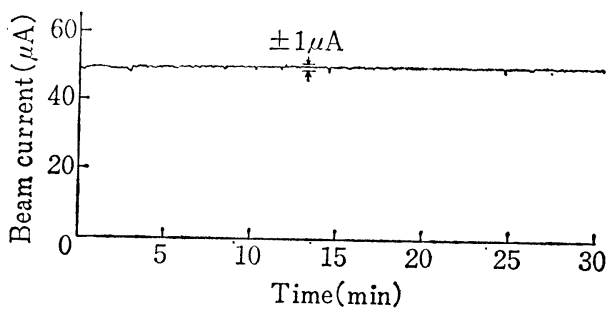

Fig. 4 Stability of the extracted beam current (proton). The beam was measured on the beam shutter.

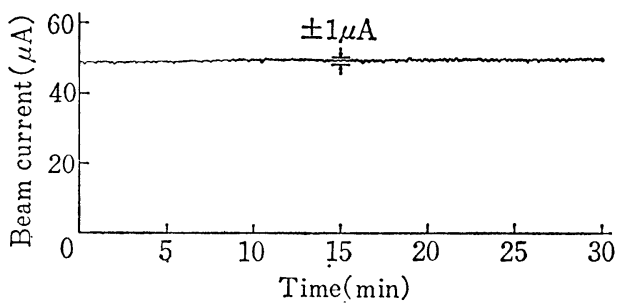

Fig. 5 Stability of the extracted beam current (deuteron). The beam was measured on the beam shutter.

to determine the beam current value.

\section{Acknowledgement}

Finally we would acknowledge the support and encouragement from Mr. Yamamoto, the former chief of the No. 5 design section, Niihama works, SHI and at the same time we would express our appreciation to all of the staff of the same section, for their useful discussion, skillful detailed design works and encouragement, and also to the staffs who belong to CGR$\mathrm{MeV}$, and, especially, Dr. Meyrand for their excellent guidance and useful advice given to us at the time of the conceptual design of CYPRIS.

\section{Reference}

1) S. Tazawa: Image Tech. \& Inform. Disp., 13, 363 (1981) 